\title{
THE MODELING OF GRAPHICAL AND ANALYTICAL DRYING PROCESS PARAMETERS RELATIONS IN $\mathrm{CO}_{2}$ ENVIRONMENT
}

\author{
NATALIA TISLINSCAIA ${ }^{1}$, MIRCEA BERNIC ${ }^{1}$, ANDREI LUPASCO ${ }^{1}$, \\ VLADIMIR ZAVIALOV $^{2}$, MIHAIL MELENCIUC ${ }^{1}$, IANA TISLINSCAIA ${ }^{1}$ \\ ${ }^{1}$ Technical University of Moldova, Department of Processes Machines and Apparatus, \\ Stefan cel Mare Bd. 168, Chisinau, MD-2004, Republic of Moldova \\ ${ }^{2}$ National University of Food Technologies, Volodymyrska str. 68, Kyiv, 01601, Ukraine
}

\begin{abstract}
The engineering calculation of such dryer could be approximately done using Iddiagrams. There is such a diagram for air based dryers graphical and analytical calculation. The use of this diagram for $\mathrm{CO}_{2}$ modified environment is impossible; because it shows the thermo-physical characteristics for air which significantly differs from those of $\mathrm{CO}_{2}$.

We made a tentative of modeling and calculate all the necessary parameters based on which there was created an Id-diagram for $\mathrm{CO}_{2}$ modified environment.

Obtained graphical relations for temperature, enthalpy, moisture content and partial pressure will allow one to use them for $\mathrm{CO}_{2}$ modified environment based dryers.
\end{abstract}

Keywords: $\mathrm{CO}_{2}$, Dryer, drying, Id-diagram, modified environment, relative humidity

\section{INTRODUCTION}

Drying is one of the main conservation methods for foods. But dehydration process in hot air flow presumes a tight contact with the oxygen, which for some products, like apples and pears is highly undesirable, as it leads to product's oxidation and as a result to quality parameters reduction. One of the methods reducing dehydration process oxygen contact of vegetal row material is $\mathrm{CO}_{2}$ modified environment use.

\section{MATERIALS AND METHODS}

The diagram was constructed for barometric pressure of $p=745 \mathbf{m m H g}=\mathbf{1 0 0 ~} \mathbf{~ P P a}$, which can be adopted as average annual air pressure. Practically the diagram can be used for any $\mathrm{CO}_{2}$ modified environment dryer calculation, as within usual deviations of air pressure the values of $\boldsymbol{i}$ and $\boldsymbol{d}$ changes slightly. Id-diagram presents a graphical interpretation of moist air enthalpy equation. It shows the relation between main moist air parameters. Each point (dot) on the diagram lights up any state (of the moist air) with quite certain parameters. To find out any of the moist air characteristics is sufficient to know only two parameters of its state.

On the diagram there are also shown the lines for temperature constant, for relative humidity constant, for partial water vapors pressure, for humid thermometer temperature constant. The moisture content that shows the quantity of vapor in an absolute dry $\mathrm{CO}_{2}$ environment, which means characterizes the weight composition of wet gas, was calculated by the formula:

\footnotetext{
${ }^{*}$ Corresponding author, email: mirceabernic@gmail.com

(C) 2017 Alma Mater Publishing House
} 


$$
d=\frac{G_{\text {vapor }}}{G_{\mathrm{CO}_{2}}}=\frac{M_{\text {vapor }}}{M_{\mathrm{CO}_{2}}} \cdot \frac{P_{p a r}}{P-P_{p a r}}
$$

where $\boldsymbol{G}_{\text {vapor }}$ - mass of water vapor in moist $\mathrm{CO}_{2} ; \boldsymbol{G}_{\mathbf{C O} 2}$ - mass of dry $\mathrm{CO}_{2}$ in the same volume; $\boldsymbol{P}_{\text {par }}$ - partial pressure; $\boldsymbol{M}_{\text {vapor }}$ - molecular weight of water vapor.

In the same time, the partial pressure will be calculated using the well-known formula:

$$
P_{p a r}=\varphi P_{s a t}
$$

Considering the molecular weight of vapor $\boldsymbol{M}_{\text {vapor }}=18$ and of $\mathrm{CO}_{2} \boldsymbol{M}_{\mathbf{C O} 2}=44$ [1], equation (1) will become:

$$
d=\frac{18}{44} \cdot \frac{\varphi P_{\text {sat }}}{P-\varphi P_{\text {sat }}}=0.409 \cdot \frac{\varphi P_{\text {sat }}}{P-\varphi P_{\text {sat }}}
$$

Since the saturated pressure can be approximated as a third degree polynomial, than:

$$
P_{\text {sat }}=0.159 \cdot t^{3}-8.7018 \cdot t^{2}+285.3 \cdot t-593.27
$$

Knowing, the foregoing, the final equation for moisture content calculation (1) will gain the form:

$$
d=0.409 \cdot \frac{\varphi \cdot\left(0.159 \cdot t^{3}-8.7018 \cdot t^{2}+285.3 \cdot t-593.27\right)}{P-\varphi \cdot\left(0.159 \cdot t^{3}-8.7018 \cdot t^{2}+285.3 \cdot t-593.27\right)}
$$

(Note: this formula is valuable for $\boldsymbol{t}>10^{\circ} \mathrm{C}$ )

\section{RESULTS AND DISCUSSION}

In such way, taking in account equation (5), one could begin construct the lines for relative humidity constant $\psi$ $=$ const . We calculated and presented graphically (Figure 1) the functional relations for $\psi=100,90,80,70,60$, $50,40,30,20,10$ and $5 \%$ relative humidity.

Moist $\mathrm{CO}_{2}$, as heat transfer agent, is characterized by the enthalpy $\boldsymbol{I}$ (heat content), equal to the sum of the enthalpies of dry gas and water vapor.

$$
I=c_{\mathrm{CO}_{2}} \cdot t+d \cdot I_{\text {vapor }}
$$

where $\boldsymbol{c} \mathrm{Coz}$ - specific heat capacity of dry $\mathrm{CO}_{2},[\mathrm{~J} /(\mathrm{kg} \cdot \mathrm{grd})], \boldsymbol{t}$ - air temperature, $\left[{ }^{\circ} \mathrm{C}\right], \boldsymbol{I}_{\text {vapor }}$ - enthalpy of overheated steam, $[\mathrm{J} / \mathrm{kg}]$.

Steam enthalpy can be calculated using the empirical formula:

$$
I_{\text {vapor }}=r_{0}+c_{\text {vapor }} \cdot t=(2493+1.97 \cdot t) \cdot 10^{3}
$$

where $\boldsymbol{r}_{\boldsymbol{0}}=\mathbf{2 4 9 3} \cdot 10^{3}-$ constant coefficient approximately equal to steam's enthalpy at $0^{\circ} \mathrm{C}, \boldsymbol{c}_{\text {vapor }}$ - specific heat capacity of steam, $[\mathrm{J} /(\mathrm{kg} \cdot \mathrm{grd})]$. 


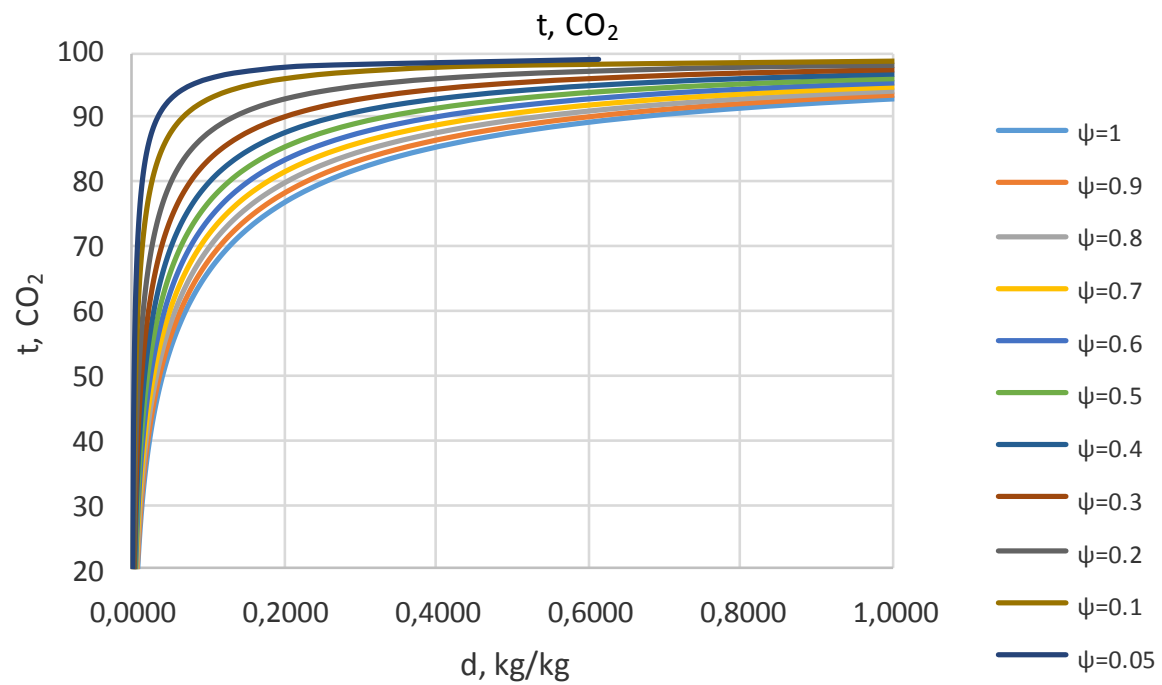

Fig. 1. The dependency diagram of temperature vs moisture content in $\mathrm{CO}_{2}$ environment, for $\psi=100,90,80,70$, $60,50,40,30,20,10$ and $5 \%$ relative humidity.

For gasiform $\mathrm{CO}_{2}$ within ideal conditions one proposed a simplified expression for specific heat capacity calculation $[\mathrm{J} /(\mathrm{kg} \cdot \mathrm{grd})][2]$ :

$$
c_{\mathrm{CO}_{2}}=818+0.988 \cdot t
$$

This way $\mathrm{CO}_{2}$ 's enthalpy can be calculated inserting formulas (5), (7) and (8) in equation (6):

$$
\begin{gathered}
I=(818+0.988 \cdot t) \cdot t+0.409 \cdot \frac{\varphi \cdot\left(0.159 \cdot t^{3}-8.7018 \cdot t^{2}+285.3 \cdot t-593.27\right)}{P-\varphi \cdot\left(0.159 \cdot t^{3}-8.7018 \cdot t^{2}+285.3 \cdot t-593.27\right)} \\
\cdot(2493+1.97 \cdot t) \cdot 10^{3}
\end{gathered}
$$

Graphically for different intervals of $\boldsymbol{d}$ (for a more precise picture), the dependency of the enthalpy on the moisture content, when $\psi=$ const can be presented in the Figure 2.

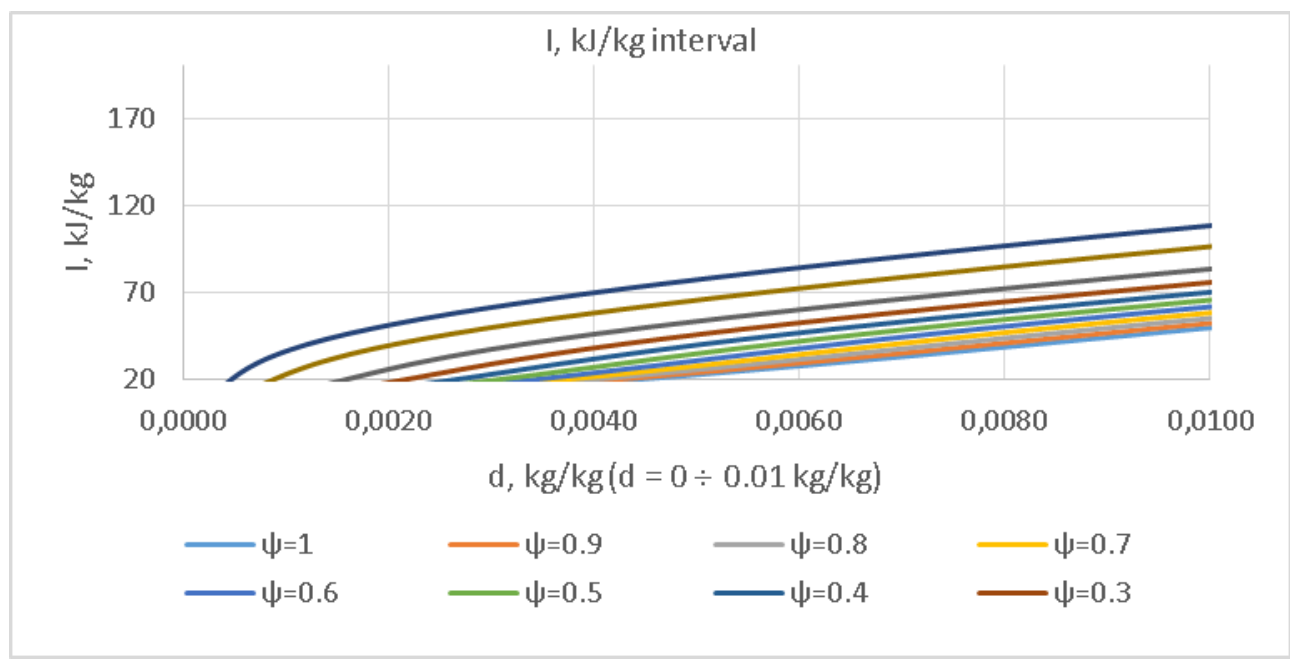

Fig. 2. Graphical dependency of the enthalpy on the moisture content, at $\psi=$ const, within $\mathrm{d}=0 \div 0.01 \mathrm{~kg} / \mathrm{kg}$ interval. 
For a clearer visualization and a more precise enthalpy definition we divided the charts in different moisture content intervals.

In the same time we calculated and represented the dependency of the enthalpy on the temperature at $\boldsymbol{\psi}=\boldsymbol{c o n s t}$, in the following graphics (Figure 3), here, likewise the previous example, we used enthalpy intervals chart division method.

Thereby for the interval $\mathbf{I}=\mathbf{0} \div \mathbf{5 0 0} \mathbf{k J} / \mathbf{k g}$, this dependence will result in Figure 3 .

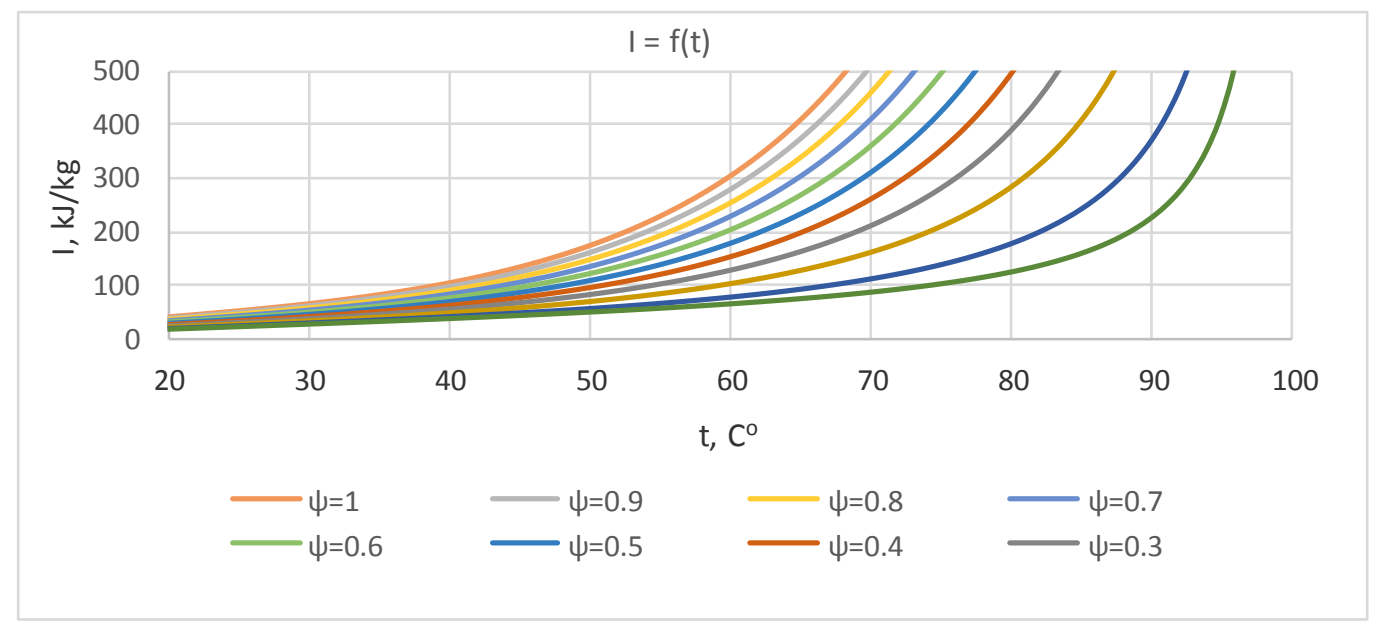

Fig. 3. Graphical dependency of the enthalpy on the temperature, at $\psi=$ const.

Temperature constants lines $\boldsymbol{t}=\boldsymbol{c o n s t}$, or isotherms, were created using equation (9), calculating $\boldsymbol{I}$ at different values of $\boldsymbol{d}$, which at $\boldsymbol{t}=$ const are graphically represented as a straight line (Figure 4). Isotherms angle augments since vapor's enthalpy is increasing.

$$
I=(818+0.988 \cdot t) \cdot t+d \cdot(2493+1.97 \cdot t) \cdot 10^{3}
$$

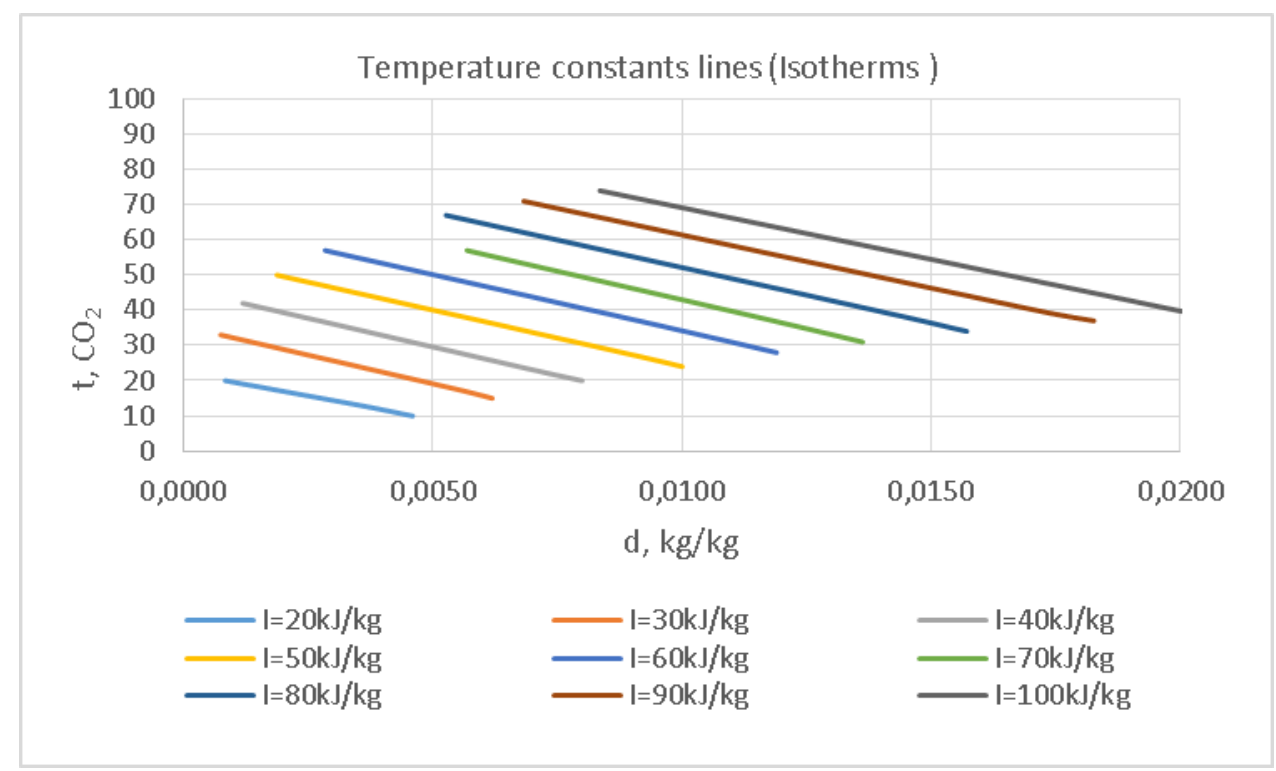

Fig. 4. Isotherms constants lines for different enthalpies.

We modeled as well the approximating functions for some enthalpies. 
Of particular interest is the moisture content determination mathematical model that includes the two factors of temperature $\left[{ }^{\circ} \mathrm{C}\right]$ and enthalpy $[\mathrm{kJ} / \mathrm{kg}]$ :

$$
d=0.002853-0.00025 \cdot t+0.000245 \cdot I
$$

$\mathrm{CO}_{2}$ partial pressure line presented in the Id-diagram was constructed based on formula (3) for different moisture content values thus $\boldsymbol{P}_{\text {par }}$ measurement scale is presented in $\mathrm{mm} \mathrm{Hg}$ (Figure 5).

$$
\begin{aligned}
d=\frac{18}{44} \cdot \frac{P_{p a}}{P-P_{p a r}} & =0.409 \cdot \frac{P_{p a r}}{P-P_{p a r}} \\
P_{p a} & =\frac{d \cdot P}{d+0.409} \\
P_{p a} & =1425 \cdot d+7.4
\end{aligned}
$$

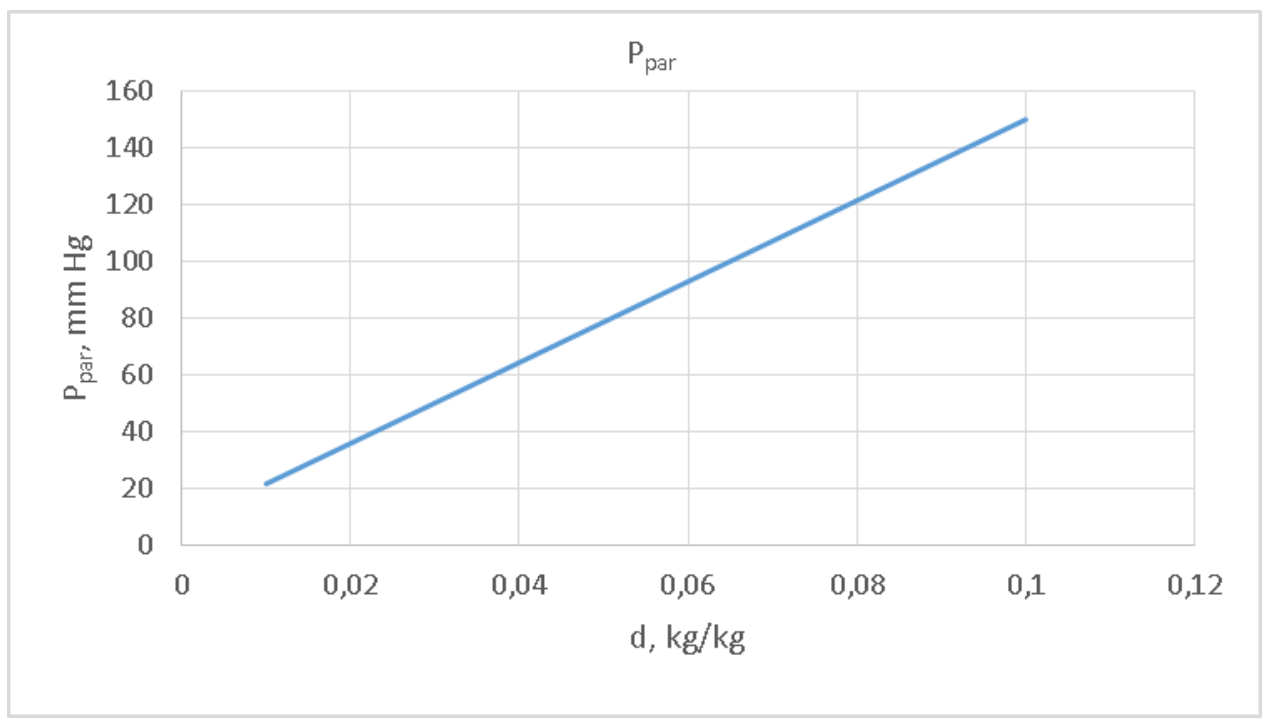

Fig. 5. $\mathrm{CO}_{2}$ gas water vapor partial pressure.

\section{CONCLUSION}

Using the resulting modeling of analytical and graphical functional relations for enthalpy, moisture content and temperature for different values of relative humidity, one can analyze drying processes as well as using those for $\mathrm{CO}_{2}$ modified environment dryers calculation.

\section{REFERENCES}

[1] Planocskij, A.N., Ramm, V.M., Kagan, S.Z., Precessy i apparaty himicheskoj tehnologii. M. Izdatel'stvo himija, 1968, p. 315.

[2] Acherkan, N.S., Spravochnik mashinostroitelja. Tom 2. M. Gosudarstvennoe nauchno tehnicheskoe izdatel'stvo mashinostroitel'noj literatury, 1956, p. 562. 